\title{
Isocyanate toughening of pCBT/organoclay nanocomposites with exfoliated structure and enhanced mechanical properties
}

\author{
T. Abt ${ }^{1 *}, J . J$. Bou $^{2}$, M. Sánchez-Soto ${ }^{1}$ \\ ${ }^{1}$ Department of Materials Science. Centre Catalá del Plàstic. Universitat Politècnica de Catalunya, BarcelonaTech. \\ C/Colom 114, 08222 Terrassa, Spain \\ ${ }^{2}$ Department of Chemical Engineering, ETSEIB, Universitat Politècnica de Catalunya, BarcelonaTech, Diagonal 647, \\ 08028 Barcelona, Spain
}

Received 10 June 2014; accepted in revised form 27 July 2014

\begin{abstract}
Cyclic butylene terephthalate $\left(\mathrm{CBT}^{\circledR}\right)$ is an interesting matrix material for the preparation of nanocomposites due to its very low, water-like melt viscosity which favours clay exfoliation. Nevertheless, polymerized CBT (pCBT) is inherently brittle. This paper reports the preparation of isocyanate-toughened nanocomposites made from CBT and organo-modified montmorillonite. The role of the organoclay as reinforcement and the polymeric isocyanate (PMDI) as toughening agent on the properties of pCBT was studied. The organoclay increased the stiffness and strength by up to $20 \%$ whereas the PMDI improved the deformation behaviour. However, the PMDI did not affect the degree of clay dispersion or exfoliation and flocculated-intercalated structures were observed. The compatibility between the pCBT matrix and clay was further increased by preparing PMDI-tethered intercalated organoclay. The modified organoclay then exfoliated during ring-opening polymerization and yielded true $\mathrm{pCBT} / \mathrm{clay}$ nanocomposites. This work demonstrates that reactive chain extension of CBT with a polyfunctional isocyanate is an effective method to obtain toughened pCBT nanocomposites. Moreover, isocyanates can enhance the compatibility between pCBT and nanofiller as well as the degree of exfoliation.
\end{abstract}

Keywords: nanocomposites, cyclic butylene terephthalate, $p C B T$, toughening, clay exfoliation

\section{Introduction}

Currently, there are considerable efforts to obtain polymer nanocomposites based on organophilic layered silicates. The driving force of these efforts is the dramatic improvement in material properties such as stiffness and strength, flame resistance, gas barrier properties and thermal stability; however, toughness typically decreases with increasing organoclay content. These improvements can be obtained with very low organoclay contents, usually less than $5 \mathrm{wt} \%$. Nevertheless, property improvements are only observed when intercalation, or better complete exfoliation, of the clay occurs and individual silicate layers disperse randomly and homogeneously on a nanoscale level in the polymer matrix. Otherwise, a flocculated-intercalated or even an immiscible structure due to poor physical interactions between the clay and the polymer matrix is usually obtained, leading to decreased mechanical and thermal performance. Therefore, exfoliated nanocomposites exhibit unique properties not shared by their micro- and macrocomposite counterparts [1-3]. The key to exfoliation is to match the polarity between the hydrophobic polymer and hydrophilic clay. A common way to increase compatibility is to render layered silicates organophilic by ion-exchange

\footnotetext{
${ }^{*}$ Corresponding author, e-mail: tobias.abt@upc.edu

(c) BME-PT
} 
reactions with cationic surfactants including primary, secondary, tertiary, and quaternary alkylammonium or alkylphosphonium cations. These surfactants lead to a larger interlayer spacing and a lower surface energy of the treated silicates, which improves polymer wetting and hence clay intercalation [3]. Moreover, some organic surfactants provide functional groups that can react with the polymer chains or initiate the polymerization of monomers, which in turn enhances the strength of the interface between clay surface and polymer [3, 4]. Despite the fact that the intercalation chemistry of polymers has been widely studied, clay exfoliation still remains a major challenge in the preparation of nanocomposites. This is partially due to the high melt viscosity of conventional thermoplastics. High melt viscosities can be overcome using ring-opening polymerization (ROP) of cyclic oligomers such as cyclic butylene terephthalate oligomers (CBT) which possess a very low, water-like melt viscosity $(0.02 \mathrm{~Pa} \cdot \mathrm{s}$ at $\left.190^{\circ} \mathrm{C}[5]\right)$. CBT oligomers undergo an entropically driven ROP in the presence of a tin-based catalyst at temperatures both above and below the melting temperature of polymerized CBT (referred to as pCBT), i.e. $T_{\mathrm{m}}=225^{\circ} \mathrm{C}$ [6]. This allows for isothermal processing below the $T_{\mathrm{m}}$ where crystallization and polymerization occur simultaneously, hence demoulding is possible without further cooling [7-9]. Nevertheless, pCBT is inherently brittle which has been ascribed to the formation of large perfect crystals with a lack of intercrystalline tie molecules [8], different crystalline morphologies [10] as well as to a low molecular weight $[11,12]$.

An increasing amount of publications dealing with pCBT/organoclay nanocomposites can be found in the literature [7, 13-21]; however, despite this considerable body of papers, little is known about the mechanical properties of these materials $[15,18,20]$ and information about the deformation behaviour is rare. Most researchers employ the low viscosity of molten or dissolved oligomers in order to obtain a CBT-intercalated organoclay. Subsequent ROP causes an increase in interlayer distance along with the disintegration of the layered clay structure. Nevertheless, obtaining complete clay exfoliation is rather difficult [13], whereas intercalated structures and flocculated-intercalated structures are more commonly observed [15, 16, 18-21]. Although several researchers have shown that the organoclay was successfully intercalated with CBT oligomers or even completely exfoliated prior to ROP, the silicate layers tended to reorganize due to the low viscosity of the molten CBT during ROP. Consequently, the exfoliated structure was lost and a flocculated-intercalated structure was obtained after polymerization $[16,19,20]$.

Similarly, clay nanocomposites made from other types of cyclic oligomers have been reported. Huang et al. [22] reported the synthesis of partially exfoliated polycarbonate nanocomposites using carbonate cyclic oligomers and organoclay. They observed clay exfoliation after mixing the cyclic oligomers with the clay in a Brabender mixer for $1 \mathrm{~h}$ at $180^{\circ} \mathrm{C}$. Subsequent ROP of the cyclics converted the matrix into linear polymer. Although no crystal features of the clay were observed in X-ray diffraction, TEM analysis revealed that partial exfoliation was obtained. González-Vidal et al. [23] synthesized nanocomposites of poly(hexamethylene terephthalate) (PHT) and organoclay via melt blending of PHT as well as by in situ ring-opening polymerization of hexamethylene terephthalate cyclic oligomers. Partially exfoliated structures were observed for samples prepared by melt blending whereas exclusively intercalated nanocomposites could be obtained by ROP. Lee et al. [17] polymerized cyclic ethylene terephthalate oligomers in the presence of an organoclay into poly(ethylene terephthalate) (PET)/clay nanocomposites. The oligomers were successfully intercalated into the clay galleries. Subsequent ROP yielded a PET matrix of high molecular weight where the clay was intercalated and partially exfoliated.

To hinder the reorganization of the silicate layers, clay platelets can be tethered to the polymer chains. Furthermore, clay-polymer coupling might enhance the exfoliation process and interfacial adhesion between the polymer matrix and clay surface. This was already effectively demonstrated for polyurethanes; coupling reactions of organoclay surfactants with isocyanates $[4,24-26]$ or with polyols $[27,28]$ have been employed in the synthesis of thermoplastic polyurethane nanocomposites, resulting in exfoliation and increased mechanical properties.

The method described herein involves a coupling reaction of the hydroxyl groups of the organic surfactants with $-\mathrm{N}=\mathrm{C}=\mathrm{O}$ functional groups of a polyfunctional isocyanate in order to intercalate the organoclay. Since the tethered isocyanate is also highly reactive toward the $\mathrm{pCBT}$ functional groups, 
specifically toward carboxyl end groups as shown in [11], pCBT is expected to be grafted onto the isocyanate-modified organoclay. To the best of our knowledge, this has not been reported in literature to date.

\section{Experimental Section}

\subsection{Materials}

Cyclic butylene terephthalate oligomers combined with a catalyst (butyl tin chloride dihydroxide) were used in this work. The material was provided as granules by Cyclics Europe GmbH (Schwarzheide, Germany). The CBT was ground into a fine powder using a mortar and pestle and vacuum dried at $80^{\circ} \mathrm{C}$ for $8 \mathrm{~h}$ prior to processing. If not otherwise stated, one-component CBT oligomers $\left(\mathrm{CBT} 160^{\circledR}\right)$ were used. For one sample two-component CBT oligomers $\left(\mathrm{CBT} 100^{\circledR}\right)$ were used for melt blending. For initiation of the ROP, $0.45 \mathrm{wt}^{\mathrm{m}} \%$ of Fascat ${ }^{\mathbb{B}} 4105$ (with respect to $\mathrm{CBT}$ ) was added to the molten oligomers. A polymeric methylene diphenyl diisocyanate, PMDI, was used for chemical modification of the organoclay as well as to toughen the pCBT nanocomposites. It was purchased from BASF Poliuretanos Iberia S.A. (Rubí, Spain) and was used as received. The PMDI was a brown, viscous liquid of grade IsoPMDI 92410. It was composed from 4,4"-methylenebis(phenyl isocyanate) and contained oligomers with an average functionality of $\sim 2.7$ and a $\mathrm{NCO}$ content of $31.8 \%$.

A commercial montmorillonite modified with a quaternary ammonium salt (i.e. methyl, tallow, bis2-hydroxyethyl, quaternary ammonium), namely Cloisite ${ }^{\circledR}$ 30B (referred to as Cl30B, Southern Clay Products, Inc., Gonzales, TX, USA) was chosen for reinforcement because the organic surfactant bears two hydroxyl groups which is a requirement for isocyanate coupling. Moreover, it was shown that this type of organoclay is compatible with poly(butylene terephthalate) (PBT) and capable of intercalation due to polar interactions between the PBT carboxyl groups and the surfactant hydroxyl groups $[29,30]$. Additionally, this type was the preferred one in patent literature [14]. The organoclay was characterized by a density of $1.98 \mathrm{~g} / \mathrm{cm}^{3}$, a moisture content of $<3 \%$ and a typical dry particle size $d_{50}$ of $<10 \mu \mathrm{m}$. The interlaminar distance $d_{001}$ was $1.85 \mathrm{~nm}$ which was confirmed by other researchers $[29,30]$. The organoclay was vacuum dried at $80^{\circ} \mathrm{C}$ for $12 \mathrm{~h}$ and stored in a desiccator over silica gel.
Analytical grade tetrahydrofuran (referred to as THF, purity $=99.5 \%$; water content $=0.05 \%$ ) was purchased from Panreac Química S.A. (Barcelona, Spain) and was used as received.

\subsection{Organoclay modification}

C130B was modified with PMDI as follows. A $500 \mathrm{~mL}$ flat bottom flask equipped with a Liebig condenser was charged with $200 \mathrm{~mL}$ THF and heated up to the boiling point. Five grams of organoclay and five grams of PMDI were added to the boiling THF under a constant stirring rate of $300 \mathrm{~min}^{-1}$ and under a stream of nitrogen gas. A relatively large PMDI excess of $150 \%$ was used in order to account for a possible reaction of PMDI with unbound or chemically bound water of the organoclay [31]. The reaction conditions were maintained for $8 \mathrm{~h}$. The solution was then allowed to cool to room temperature and was filtered through a paper filter. The filtrate was washed thoroughly three times with fresh THF in order to remove unreacted isocyanate and was then vacuum dried at $60^{\circ} \mathrm{C}$ for $24 \mathrm{~h}$ and stored in a desiccator over silica gel. The isocyanate-grafted organoclay was referred to as PMDI- $g$-Cl30B.

\subsection{Sample preparation}

Two processing routes, melt blending (MB) and solvent blending $(\mathrm{SB})$, were employed to prepare $\mathrm{pCBT} / \mathrm{Cl} 30 \mathrm{~B}$ nanocomposites. The studied clay content was 1,2 and $3 \mathrm{wt} \%$. Two different groups of samples were prepared using each processing route, namely CBT/PMDI/Cl30B ternary blends (each containing $1 \mathrm{wt} \%$ of PMDI) and CBT/PMDI- $g$-Cl30B binary blends.

Melt blending was conducted in a lab-scale batch mixer (Brabender Plasti-Corder W50EHT, Brabender GmbH \& Co. KG, Duisburg, Germany), equipped with a torque measuring system. Approximately $40 \mathrm{~g}$ of previously dried CBT and the corresponding amount of either organoclay or chain extender and organoclay were in situ polymerized in the batch mixer at a temperature of $230^{\circ} \mathrm{C}$ for $15 \mathrm{~min}$, a rotor speed of $60 \mathrm{~min}^{-1}$ and under a protective nitrogen blanket. The materials were then collected from the mixing chamber, ground into granules, vacuum dried for $8 \mathrm{~h}$ at $80^{\circ} \mathrm{C}$ and subsequently compression moulded at a temperature of $250^{\circ} \mathrm{C}$ and a pressure of $4 \mathrm{MPa}$ for $5 \mathrm{~min}$ in order to obtain flat samples for testing. Compression moulding was performed in an IQAP LAP PL-15 hot plate press equipped with 
temperature- and pressure-controlled plates (IQAP Masterbatch group SL, Barcelona, Spain). The cooling rate of the cold stage of the hot plate press was previously determined to be approximately $-50^{\circ} \mathrm{C} / \mathrm{min}$.

Solvent blending was used to homogeneously disperse either the organoclay or chain extender and organoclay in CBT prior to ROP. It was performed with approximately $20 \mathrm{~g}$ of CBT and organoclay dry blend in $50 \mathrm{~mL}$ THF at room temperature at a stirring speed of $300 \mathrm{~min}^{-1}$ for $1 \mathrm{~h}$. The dispersions were then vacuum dried at $80^{\circ} \mathrm{C}$ for $8 \mathrm{~h}$, ground into a fine powder using a mortar and pestle and again vacuum dried again at $80^{\circ} \mathrm{C}$ for at least 3 days to completely remove the THF. Approximately $13 \mathrm{~g}$ of the dried blends were in situ polymerized at a temperature of $230^{\circ} \mathrm{C}$ for 15 min during compression moulding in the previously mentioned hot plate press. All prepared films from both processing routes had dimensions of ca. $150 \times 150 \times 0.5 \mathrm{~mm}^{3}$ and were used to extract samples for further characterization. In addition, pristine pCBT specimens were also prepared by both processing routes for comparison.

In addition to the previously mentioned groups of samples, another sample was prepared as follows. A ternary blend of two-component CBT100 (i.e. oligomers without catalyst), $1 \mathrm{wt} \%$ of PMDI and $3 \mathrm{wt} \%$ of $\mathrm{Cl} 30 \mathrm{~B}$ was melt blended at $200^{\circ} \mathrm{C}$, $180 \mathrm{~min}^{-1}$ and $\mathrm{N}_{2}$ atmosphere for $2 \mathrm{~h}$. The temperature was then raised to $230^{\circ} \mathrm{C}$, the rotor speed was reduced to $60 \mathrm{~min}^{-1}$ and the transesterification catalyst was added in order to initiate the ROP. The blend was allowed to polymerize for $15 \mathrm{~min}$. This sample was referred to as $\mathrm{pCBT100/PMDI/C130B}$ $96 / 1 / 3$. The purpose of this method was to take advantage of the low viscosity of the molten CBT oligomers in such way that they would swell the organoclay by diffusing into the clay galleries, causing exfoliation of the clay particles upon polymerization, as demonstrated by other researchers [13, 16]. Processing details of all prepared samples are compiled in Table 1.

\subsection{Characterization}

Isocyanate grafting onto the clay platelets was verified using FT-IR analysis. Infrared spectra were recorded on a Nicolet 6700 FT-IR/Attenuated Total Reflection spectrometer (Thermo Fisher Scientific, Waltham, MA, USA). Spectra were obtained in the wavenumber interval between 4000 and $400 \mathrm{~cm}^{-1}$ at a scan number of 32 scans and a resolution of $4 \mathrm{~cm}^{-1}$. The degree of clay exfoliation was determined using X-ray diffraction (XRD) and transmission electron microscopy (TEM). XRD diffraction data was collected on a Bruker D4 Endeavor using Ni-filtered $\mathrm{Cu} \mathrm{K} \mathrm{K}_{\alpha}$ radiation $(\lambda=1.54 \AA, V=40 \mathrm{kV}$; $I=40 \mathrm{~mA}$ ). XRD scattering patterns were recorded in the diffraction angle $(2 \theta)$ range of $1.5^{\circ}<2 \theta<10^{\circ}$ at a scanning rate of $8 \mathrm{~s} / \mathrm{step}$ using steps of $0.02^{\circ}$. TEM analysis was performed on a Jeol JEM2011 transmission electron microscope (Jeol, Tokyo, Japan) using an acceleration voltage of $200 \mathrm{kV}$. Thin $(60-100 \mathrm{~nm})$ specimens were prepared at room temperature using an ultramicrotome (Leica EM UC6, Leica Microsystems GmbH, Wetzlar, Germany). The samples were further characterized using differential scanning calorimetry (DSC) on a PerkinElmer Pyris 1 device calibrated with indium. DSC was carried out under dry nitrogen atmosphere using a sample weight of $8-12 \mathrm{mg}$. Samples were heated from 30 to $250^{\circ} \mathrm{C}$ at a heating rate of $10^{\circ} \mathrm{C} / \mathrm{min}$, followed by an isothermal step of 3 minutes and then

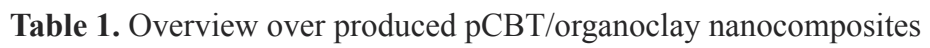

\begin{tabular}{|l|c|c|c|}
\hline \multicolumn{1}{|c|}{ Sample designation } & Processing & $\begin{array}{c}\text { Temperature } \\
{\left[{ }^{\circ} \mathbf{C}\right]}\end{array}$ & $\begin{array}{c}\text { Time } \\
{[\text { min }]}\end{array}$ \\
\hline pCBT/PMDI/Cl30B 98/1/1-MB & MB & $230+250^{*}$ & $15+5^{*}$ \\
\hline pCBT/PMDI/Cl30B 98/1/1-SB & SB & 230 & 15 \\
\hline pCBT/PMDI-g-Cl30B 1\%-MB & MB & $230+250^{*}$ & $15+5^{*}$ \\
\hline pCBT/PMDI-g-Cl30B 2\%-MB & MB & $230+250^{*}$ & $15+5^{*}$ \\
\hline pCBT/PMDI-g-Cl30B 3\%-MB & MB & $230+250^{*}$ & $15+5^{*}$ \\
\hline pCBT/PMDI-g-Cl30B 1\%-SB & SB & 230 & 15 \\
\hline pCBT/PMDI-g-Cl30B 2\%-SB & SB & 230 & 15 \\
\hline pCBT/PMDI-g-Cl30B 3\%-SB & SB & 230 & 15 \\
\hline pCBT100/PMDI/C130B 96/1/3-MB & MB & $200+230+250$ & $120+15+5$ \\
\hline
\end{tabular}

MB: melt blending; SB: solvent blending

*A temperature of $230+250^{\circ} \mathrm{C}$ and a time of $15+5$ min indicate that the material was melt blended at $230^{\circ} \mathrm{C}$ for 15 min and then compression moulded at $250^{\circ} \mathrm{C}$ for 5 min. 
cooled from 250 to $30^{\circ} \mathrm{C}$ at a rate of $-10^{\circ} \mathrm{C} / \mathrm{min}$. The second heating run was performed in the same temperature range and at a heating rate of $10^{\circ} \mathrm{C} / \mathrm{min}$. The melting enthalpy, $\Delta H_{\mathrm{m}}$, of the first heating run was used to calculate the degree of crystallinity, $X_{\mathrm{C}}$, of the samples according to Equation (1):

$X_{\mathrm{C}}=\frac{\Delta H_{\mathrm{m}}}{\Delta H_{\mathrm{m}}^{0}\left(1-W_{\mathrm{f}}\right)} \cdot 100 \%$

where $\Delta H_{\mathrm{m}}$ is the measured melting enthalpy, $\Delta H_{\mathrm{m}}^{0}$ is the melting enthalpy for a fully perfect crystalline PBT which is found in literature to be $142 \mathrm{~J} / \mathrm{g}$ [8] and $W_{\mathrm{f}}$ is the weight fraction of the clay reinforcement. The nanocomposites were characterized by dynamic mechanical thermal analysis (DMTA) using a Q800 TA device (TA Instruments, New Castle, DE, USA) in tensile mode at a frequency of $1 \mathrm{~Hz}$ and a strain of $0.05 \%$. The temperature range was set from 30 to $210^{\circ} \mathrm{C}$ at a heating rate of $2{ }^{\circ} \mathrm{C} / \mathrm{min}$ and samples had dimensions of ca. $27 \times 5 \times 0.5 \mathrm{~mm}^{3}$. The relative viscosity, $\eta_{\text {rel }}$, of samples dissolved in 1,1,1,3,3,3-hexafluoroisopropanol (referred to as HFIP, Apollo Scientific, Manchester, UK) at a concentration of $10 \mathrm{mg} / \mathrm{mL}$ was determined using a Cannon-Ubbelohde viscometer (Cannon Instrument Co., Pennsylvania, USA) operated at $25 \pm 0.1^{\circ} \mathrm{C}$ in a water bath. Three measurements were carried out for each reported value. Gel permeation chromatography (GPC) was performed on an Agilent Technologies 1200 Series modular system (Agilent Technologies, Santa Clara, CA, USA) which was comprised of an Agilent 1260 variable wavelength detector operated at a temperature of $35^{\circ} \mathrm{C}$. A PL HFIPgel column from Agilent was used to perform separation. Mobile phase was HFIP stabilized with $2.72 \mathrm{~g} / \mathrm{L}$ sodium fluoroacetate to prevent polyelectrolyte effect. A flow rate of $1.0 \mathrm{~mL} / \mathrm{min}$ was employed. The pressure of the column was 75 bars. The injection volume was $100 \mu \mathrm{L}$ of $1 \mathrm{mg} / \mathrm{mL}$ polymer solution. Low dispersed poly(methyl methacrylate) samples were used as internal standards. Molar mass data were calculated using Agilent Chemstation software. The mechanical properties were determined by tensile tests according to ISO 527 at room temperature and at a crosshead speed of $10 \mathrm{~mm} / \mathrm{min}$ on a Galdabini Sun 2500 universal testing machine (Galdabini, Cardano al Campo, Italy), equipped with a video extensometer to measure strain. Type 1BA specimens were extracted from the above described sample films. A minimum of five specimens were tested for each reported value.

\section{Results and discussion \\ 3.1. PMDI/organoclay grafting}

A grafting reaction between PMDI and the hydroxyl groups of the quaternary ammonium salt of the organoclay is proposed in Figure 1.

FT-IR spectra of pristine and PMDI-grafted Cl30B in Figure 2 exhibit the characteristic bands of montmorillonite due to Al-O stretching at 3630, 919, 850 and $624 \mathrm{~cm}^{-1}, \mathrm{Si}-\mathrm{O}$ stretching at $1048 \mathrm{~cm}^{-1}$, and asymmetric and symmetric stretching of methylene groups in hydrocarbon chains of the quaternary ammonium salt at 2852 and $2925 \mathrm{~cm}^{-1}$, respectively [4, 32, 33]. It can be seen that PMDI-grafted organoclay exhibited new absorption bands at wavenumbers of 1716 and $1536 \mathrm{~cm}^{-1}$ (c.f. insert in Figure 2) which were attributed to the stretching and deformation vibration of hydrogen bonded $\mathrm{C}=\mathrm{O}$ and $\mathrm{N}-\mathrm{H}$, respectively $[4,34]$. These absorption bands are characteristic of a urethane group, suggesting that PMDI had reacted with the quaternary ammonium salt of the organoclay.

Further evidence of a successful isocyanate grafting onto the clay surface is provided by XRD analysis; the diffraction patterns of pristine $\mathrm{Cl} 30 \mathrm{~B}$ and PMDI$g$-Cl30B are illustrated in Figure 3. As mentioned in section 2.1, pristine $\mathrm{Cl} 30 \mathrm{~B}$ has a basal spacing of $1.85 \mathrm{~nm}$ according to the literature. The $\mathrm{Cl} 30 \mathrm{~B}$ used in this work exhibited a reflection at $2 \theta=5.2^{\circ}$ which corresponds to a slightly lower basal spacing, namely $1.7 \mathrm{~nm}$, most likely due to some agglomeration [3].

In contrast, the diffraction pattern of PMDI- $g$ $\mathrm{Cl} 30 \mathrm{~B}$ shows two reflections at $2 \theta=3.0$ and $6.4^{\circ}$ which correspond to basal spacings of 2.9 and $1.4 \mathrm{~nm}$, respectively. The reflection at $2 \theta=6.4^{\circ}$ can be ascribed to the second diffraction order. This suggests that the PMDI intercalated into the clay galleries and was grafted onto the platelet surface. Consequently, the interlayer distance between clay galleries markedly increased and thus a weakening of the interlayer interactions with facilitated exfoliation during processing can be expected.

\subsection{Optimization of processing parameters}

In previous literature it was reported that the presence of organoclay can delay the ROP of CBT, 

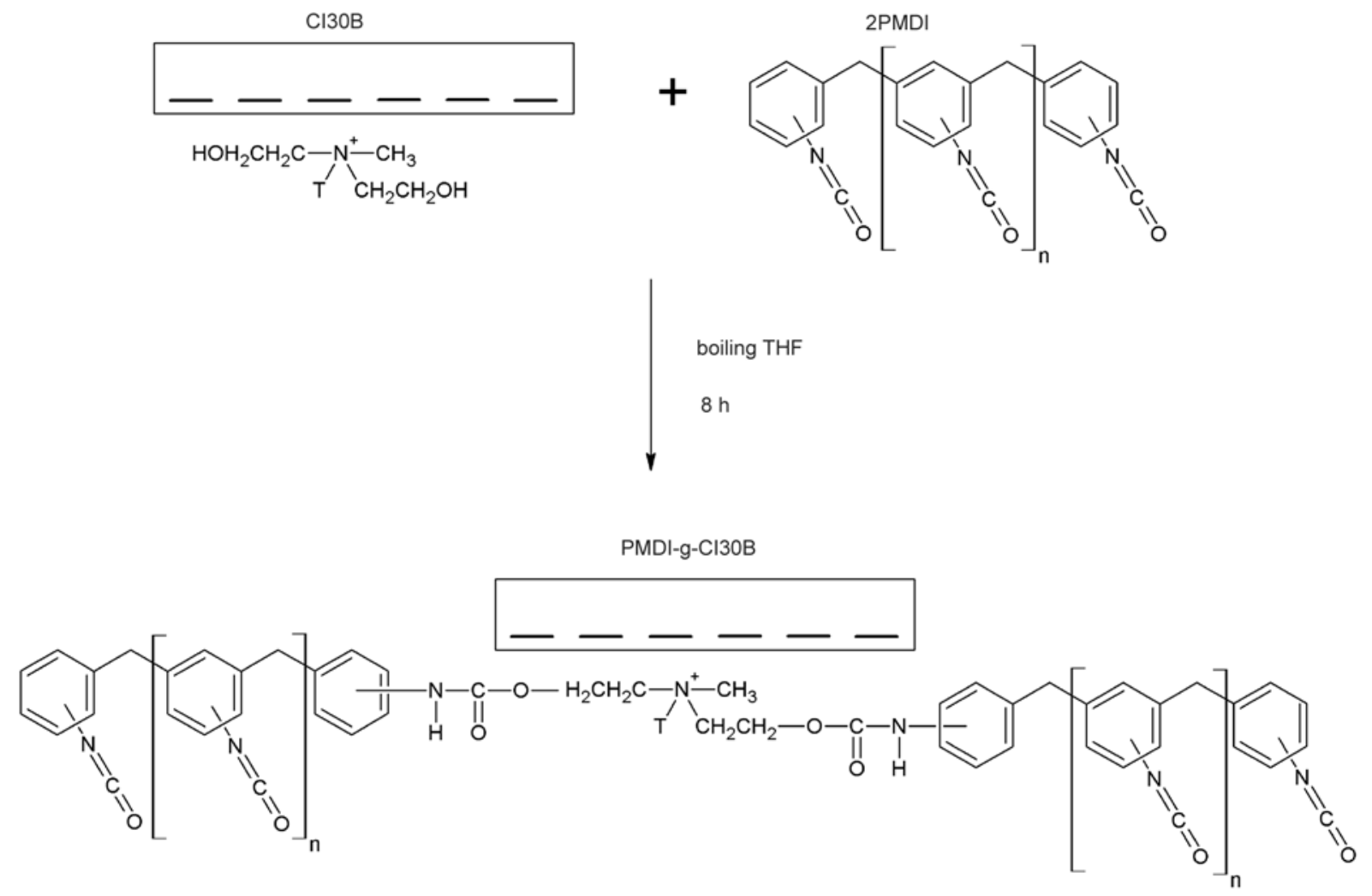

Figure 1. Chemical modification of $\mathrm{Cl} 30 \mathrm{~B}$ with PMDI. $\mathrm{T}$ is tallow $(\sim 65 \% \mathrm{C} 18 ; \sim 30 \% \mathrm{C} 16 ; \sim 5 \% \mathrm{C} 14)$.

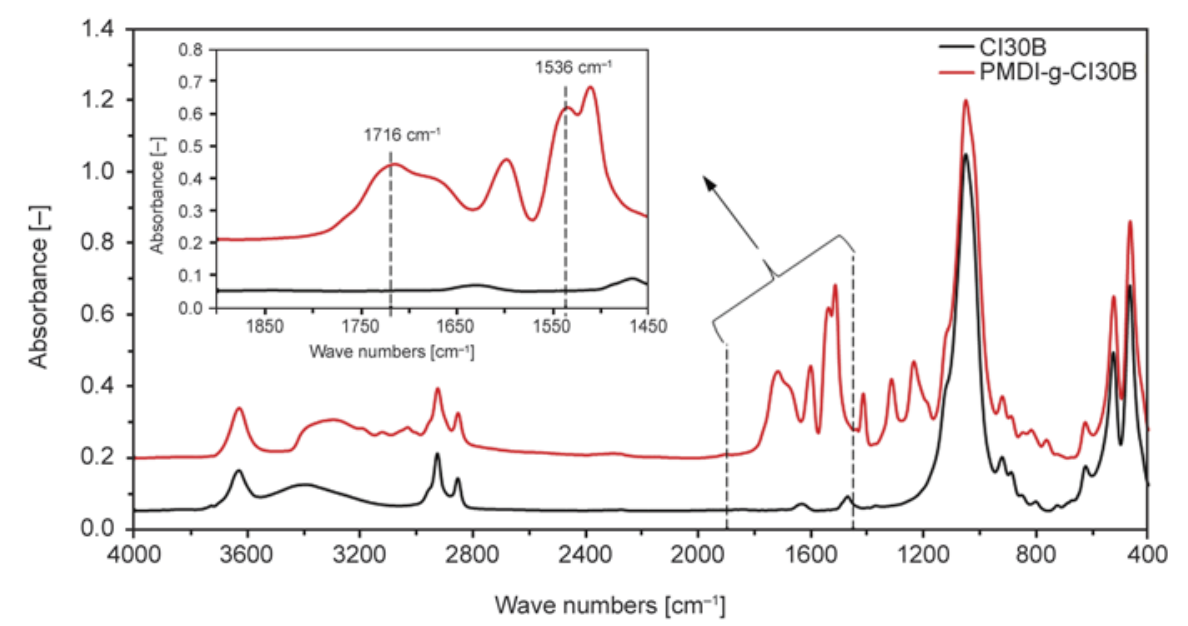

Figure 2. FT-IR spectra of unmodified Cl30B and PMDI- $g$-Cl30B in the wavenumber range $4000-400 \mathrm{~cm}^{-1}$ with inset in the wavenumber range $1900-1450 \mathrm{~cm}^{-1}$

shifting the polymerization towards higher temperatures and affecting the conversion and molecular weight of the resulting pCBT $[7,16]$. Therefore, prior to sample preparation, the optimum processing parameters were determined in order to achieve a fully converted high-molecular weight pCBT. This was achieved using preliminary torque versus time measurements in the batch mixer. In addition, a binary CBT/Cl30B blend containing $1 \mathrm{wt} \%$ of clay was prepared for comparison. Figure 4 depicts the torque curves of pristine CBT and a CBT blend of each sample group with an organoclay content of $1 \mathrm{wt} \%$.

The torque signal of pristine CBT was first detected after 3 min which was considered to be the onset of the ROP. Before this time, the melt viscosity of the molten CBT was below the detection limit of the measuring system. The torque curve reached a plateau after $9 \mathrm{~min}$ at ca. $6 \mathrm{Nm}$. It then slowly increased until it reached a maximum of $7 \mathrm{Nm}$ after $30 \mathrm{~min}$. The $\mathrm{CBT} / \mathrm{Cl} 30 \mathrm{~B}$ blend showed a $3 \mathrm{~min}$ delayed torque onset and an overall lower torque 


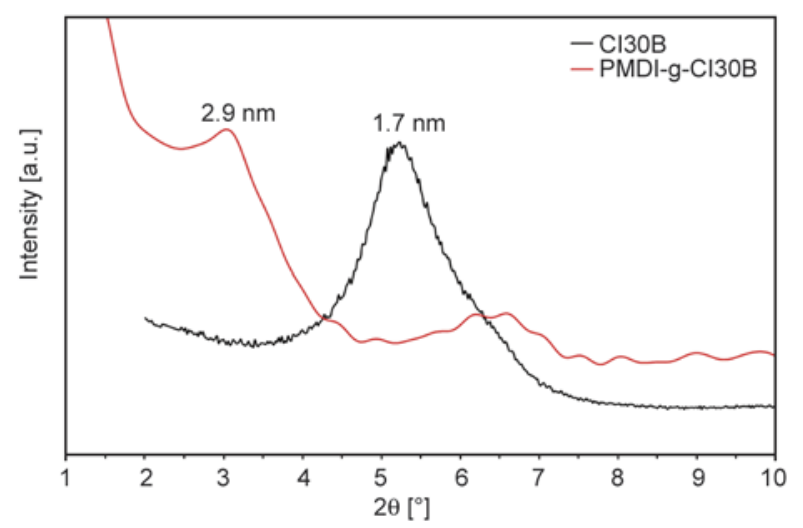

Figure 3. XRD diffraction patterns of pristine $\mathrm{Cl} 30 \mathrm{~B}$ and PMDI-g-Cl30B

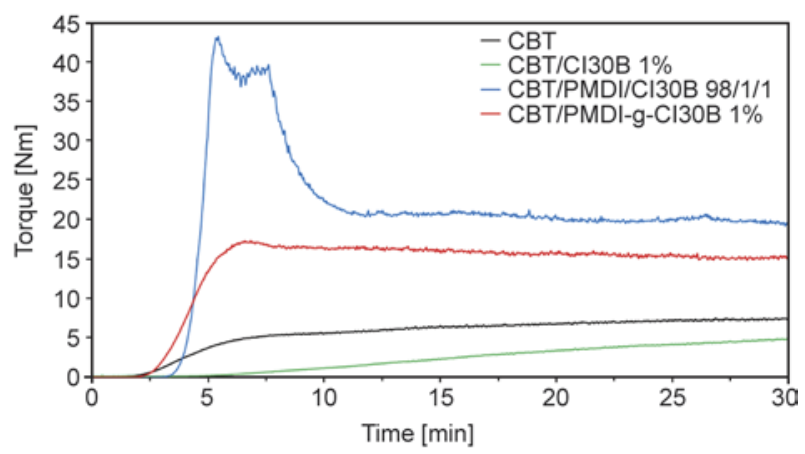

Figure 4. Torque versus time plots of $\mathrm{CBT}, \mathrm{CBT} / \mathrm{Cl} 130 \mathrm{~B}$ 1\%, CBT/PMDI/Cl30B 98/1/1 and CBT/PMDI$g-\mathrm{Cl} 130 \mathrm{~B} 1 \%$ blends polymerized at $230^{\circ} \mathrm{C}$ and $60 \mathrm{~min}^{-1}$ under nitrogen atmosphere

level relative to pristine CBT. This data confirms previous literature $[7,16]$ that the organoclay delays the ROP and affects the final molecular weight. A possible explanation is that bound crystal water of the clay may have affected the CBT catalyst activity [35] and also caused pCBT hydrolysis.

In comparison, the ternary blend exhibited less delay in the torque onset, reaching a maximum level of $43 \mathrm{Nm}$ after $5 \mathrm{~min}$ due to the fast reaction between PMDI and growing pCBT chains [11]. The torque decreased and reached a stable plateau value of $20 \mathrm{Nm}$ which is considerably higher than that of neat CBT, suggesting a relatively higher molecular weight. Similarly, the CBT/PMDI- $g$-Cl30B blend showed a torque onset equal to pristine CBT, a maximum torque of $17 \mathrm{Nm}$ after $7 \mathrm{~min}$ and essentially maintained this torque level until the end of the experiment.

On one hand, this demonstrates the reactivity of PMDI-g-Cl30B since no extra isocyanate was added, indicating that the organoclay modification was effective. It also shows that the addition of PMDI to $\mathrm{CBT} / \mathrm{Cl} 30 \mathrm{~B}$ blends, as well as the addition of PMDI-grafted $\mathrm{Cl} 30 \mathrm{~B}$ to $\mathrm{CBT}$, enhances the polymerization onset time and apparently the final molecular weight. It is noteworthy that the molten pCBT/ PMDI-g-Cl30B blend was completely transparent after a 30 min mixing time, indicating clay exfoliation, whereas the $\mathrm{pCBT} / \mathrm{Cl} 30 \mathrm{~B}$ blends were somewhat hazy, which became more noticeable when PMDI was present in the ternary blends. In light of the observed torque maxima, a polymerization time of $15 \mathrm{~min}$ was chosen for the ternary blends as well as for the binary blends containing PMDI-g-Cl30B.

\subsection{Relative viscosity and GPC analysis}

Relative viscosity measurements in combination with GPC data were used to estimate the molecular weights of some samples (c.f. Table 2). It is noteworthy that all samples were filtered prior to GPC analysis which was not the case for relative viscosity determination. Therefore, $\eta_{\text {rel }}$ values represent the samples in their entirety whereas GPC data only accounts for the soluble portion of the blend. In order to distinguish the influence of 'free' isocyanate in ternary blends in interaction with the organoclay on the molecular weight of $\mathrm{pCBT}$, the melt blended sample pCBT/PMDI $1 \%$ is also listed in Table 2.

As mentioned in section 3.2, the presence of organoclay can delay the ROP of CBT and affect the conversion and molecular weight of the resulting pCBT. This effect can also be observed here when

Table 2. Relative viscosity and GPC data of pCBT/organoclay nanocomposites

\begin{tabular}{|l|c|r|r|c|}
\hline \multicolumn{1}{|c|}{ Sample designation } & \multirow{2}{*}{\begin{tabular}{c} 
Viscosity, \\
\cline { 3 - 5 }
\end{tabular}} & {$[-]$} & \multicolumn{2}{c|}{ GPC } \\
\cline { 3 - 5 } & & $\begin{array}{c}\mathbf{M}_{\mathbf{n}} \\
{[\mathbf{k g} / \mathbf{m o l}]}\end{array}$ & $\begin{array}{c}\mathbf{M}_{\mathbf{w}} \\
{[\mathbf{k g} / \mathbf{m o l}]}\end{array}$ & $\begin{array}{c}\text { PDI } \\
{[-]}\end{array}$ \\
\hline pCBT-MB & 2.33 & 28.7 & 62.4 & 2.2 \\
\hline pCBT/PMDI 1\%* & 3.86 & 41.1 & 137.6 & 3.3 \\
\hline pCBT/Cl30B 1\%-MB & 2.55 & 24.9 & 61.5 & 2.5 \\
\hline pCBT/PMDI/Cl30B 98/1/1-MB & 3.26 & 31.9 & 100.3 & 3.1 \\
\hline pCBT/PMDI-g-Cl30B 1\%-MB & 2.43 & 28.8 & 68.1 & 2.4 \\
\hline pCBT/PMDI-g-Cl30B 1\%-SB & 2.60 & 30.8 & 75.0 & 2.4 \\
\hline
\end{tabular}

${ }^{*}$ Gel content: $31.5 \%$ 
comparing pristine $\mathrm{pCBT}-\mathrm{MB}$ and $\mathrm{pCBT} / \mathrm{Cl} 30 \mathrm{~B}$ $1 \%$-MB. The latter sample exhibited a relatively lower molecular weight but also a higher viscosity. Therefore, this higher viscosity may be solely ascribed to the presence of the organoclay.

It can be seen that the addition of $1 \mathrm{wt} \%$ of PMDI to pCBT considerably increased both viscosity and molecular weight of the pCBT. Moreover, this composition resulted in a gel content of $31.5 \%$ [11] which is indicative of successful chain extension. A similar, though less pronounced, increase in $\eta_{\mathrm{rel}}, M_{\mathrm{n}}$ and $M_{\mathrm{w}}$ was found for the ternary blend. In contrast, binary blends with PMDI-grafted organoclay showed little improvement in both viscosity and molecular weight. This can be explained by the fact that no 'free' isocyanate was present in these samples and only a small amount of PMDI grafted to the clay platelets was available for chain extension. Nevertheless, binary blends with PMDI-g-Cl30B showed a slight increase in molecular weight as compared to $\mathrm{pCBT} / \mathrm{Cl} 30 \mathrm{~B} 1 \%-\mathrm{MB}$.

The polydispersity index (PDI) of pCBT was close to the theoretical PDI of 2.0, typical for ring-opening polymerizations $[6,36]$. The PDI increased with increasing degree of chain extension. As such, the highest PDI values were found for samples with 'free' isocyanate, i.e. pCBT/PMDI $1 \%$ and $\mathrm{pCBT} /$ PMDI/Cl30B 98/1/1-MB. This demonstrates that PMDI and PMDI- $g$-Cl30B improve the molecular weight of $\mathrm{pCBT} / \mathrm{Cl} 30 \mathrm{~B}$ nanocomposites.

\subsection{XRD analysis}

The degree of exfoliation of the various pCBT/ organoclay composites was studied using XRD analysis; the diffraction patterns are illustrated in Figures 5 and 6.

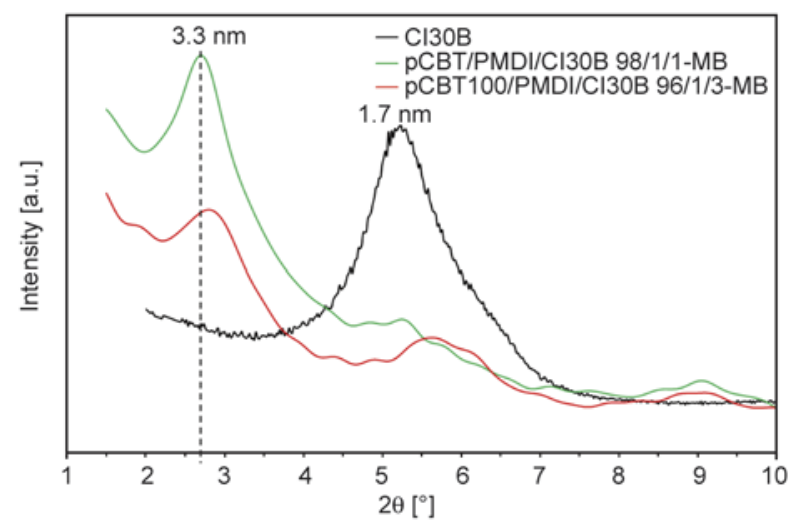

Figure 5. XRD diffraction patterns of $\mathrm{Cl} 30 \mathrm{~B}$ and the corresponding melt blended pCBT nanocomposites
The diffraction patterns of the two pCBT nanocomposites in Figure 5 are quite similar to each other but different from the one of pristine $\mathrm{Cl} 30 \mathrm{~B}$. They show two reflections at $2 \theta=2.7^{\circ}$ and $5.2-5.4^{\circ}$ which correspond to basal spacings of $3.3 \mathrm{~nm}$ and $1.7-$ $1.64 \mathrm{~nm}$. The first reflection suggests that most of the organoclay was intercalated by $\mathrm{pCBT}$, whereas the reflection at higher diffraction angles again can be attributed to the second diffraction order. Overall, an intercalated-flocculated structure can be deduced [3]. The weak peak around $2 \theta=9^{\circ}$ is the (001) reflection of pCBT and is also present in WAXS diffraction patterns, as seen for instance in [8]. These samples represent two groups; pCBT/ $\mathrm{PMDI} / \mathrm{Cl} 30 \mathrm{~B}$ ternary blends and the sample pCBT100/PMDI/Cl30B 96/1/3 which was melt blended for $2 \mathrm{~h}$ in order to swell the organoclay prior to ROP. Moreover, these samples also represent the studied organoclay content range. It can be concluded that within the studied range melt blending produces an intercalated-flocculated nanocomposite structure, regardless of clay content. The presence of PMDI or swelling the organoclay in molten low-viscous CBT oligomers apparently did not affect the basal spacing.

The diffraction patterns of PMDI-grafted organoclay and the corresponding melt blended and solvent blended nanocomposites are depicted in Figure 6. No reflections can be observed in the melt blended sample, suggesting that the organoclay was largely exfoliated and true nanocomposites were formed. The weak reflection around $2 \theta=6^{\circ}$ in the solvent blended sample suggests that part of the clay was agglomerated. Nevertheless, the peak intensity is very low; indicating that an insignificant amount of agglomeration was present, probably due

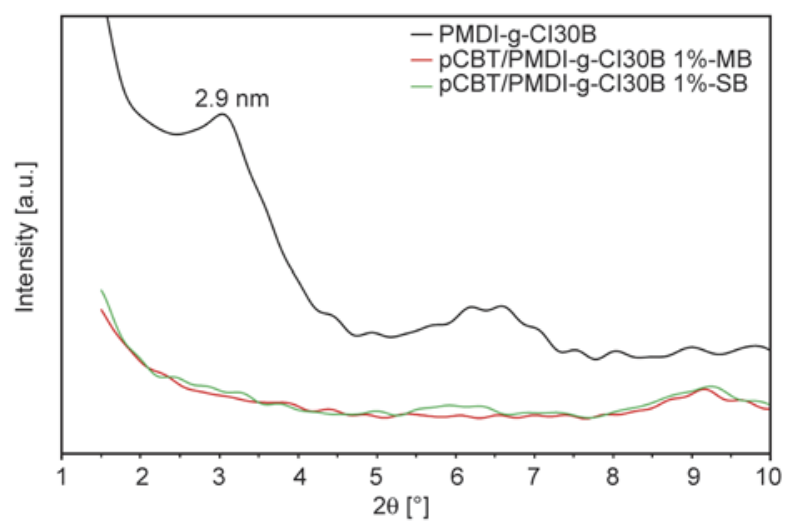

Figure 6. XRD diffraction patterns of PMDI- $g-\mathrm{Cl} 30 \mathrm{~B}$ and the corresponding melt blended and solvent blended pCBT nanocomposites 
to clay platelet reorganization during ROP in the absence of shear flow. Again, the weak reflection around $2 \theta=9^{\circ}$ originates from $\mathrm{pCBT}$, as previously mentioned.

These results suggest that the PMDI-grafted organoclay was able to be largely exfoliated and randomly dispersed in the pCBT matrix because the clay was previously intercalated with PMDI. Moreover, because PMDI was grafted onto the organoclay surface it is very likely that $\mathrm{pCBT}$ end groups reacted with the PMDI and therefore facilitated clay exfoliation.

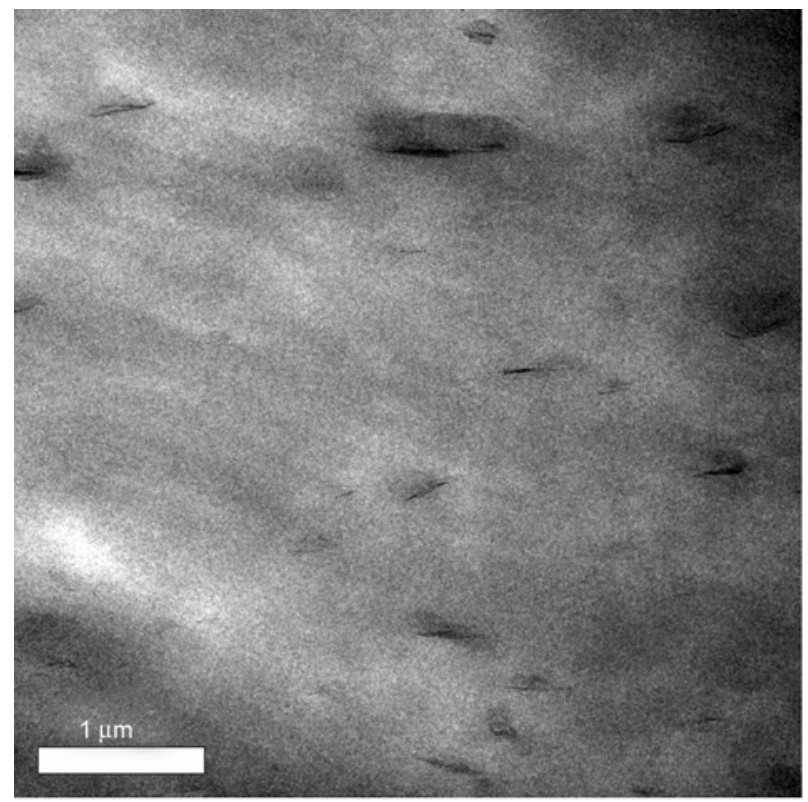

a)

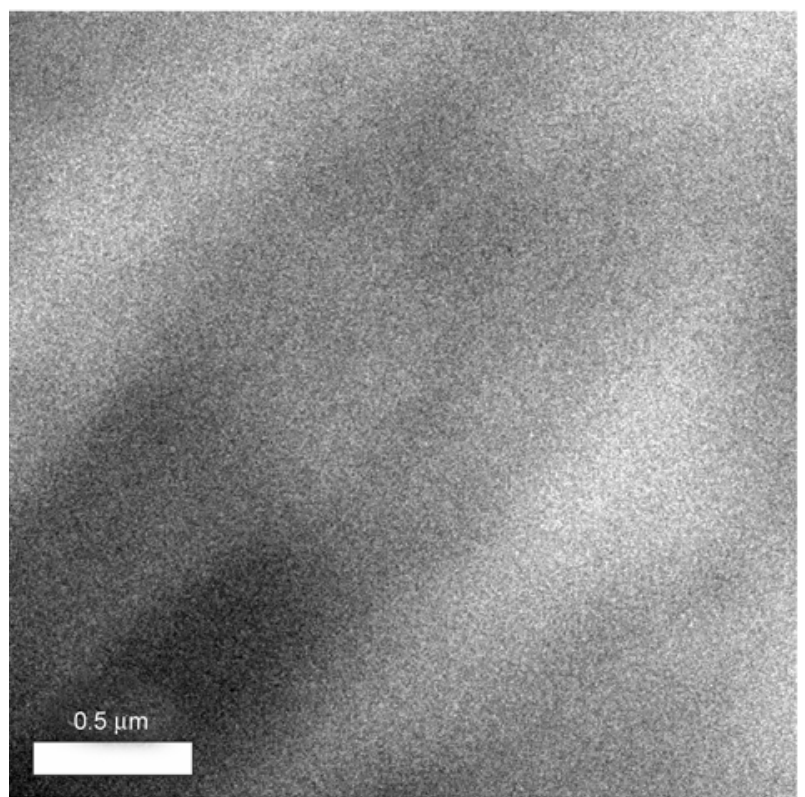

c)

\subsection{TEM analysis}

The TEM micrographs of ternary blends and PMDIgrafted binary blends are depicted in Figure 7. The effect of the clay modification is best observed at a larger scale when comparing Figures $7 \mathrm{a}$ and $7 \mathrm{c}$, whereas Figures $7 \mathrm{~b}$ and $7 \mathrm{~d}$ represent high magnification details of the two samples. It can be noticed that ternary blends (c.f. Figure $7 \mathrm{a}$ and $7 \mathrm{~b}$ ) exhibited micron-sized clay tactoids, confirming an intercalated-flocculated structure. Nevertheless, a partial clay intercalation with increased $d$ spacing is apparent in Figure $7 b$ for this sample.

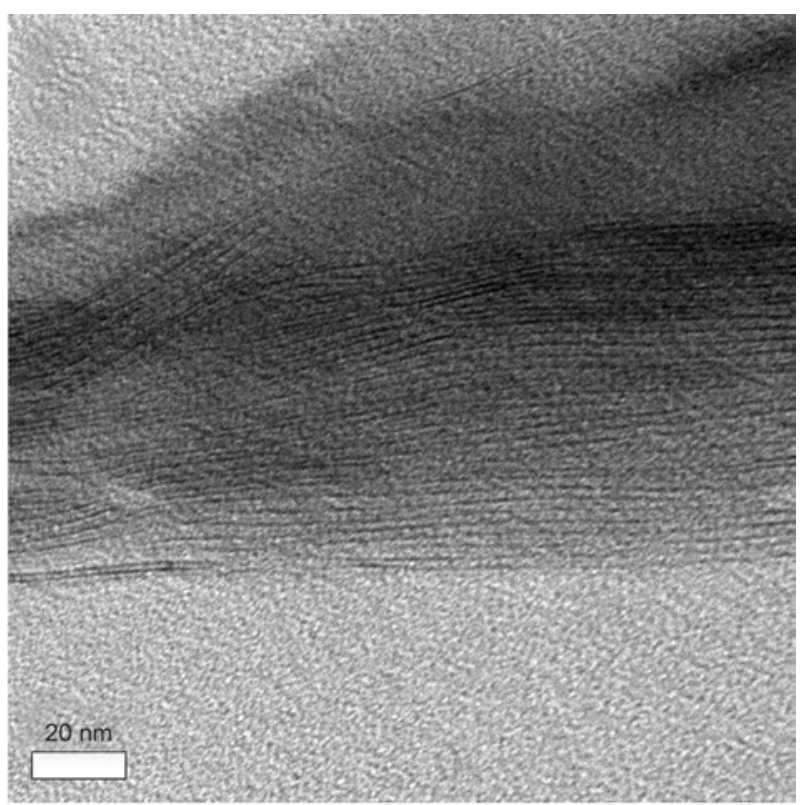

b)

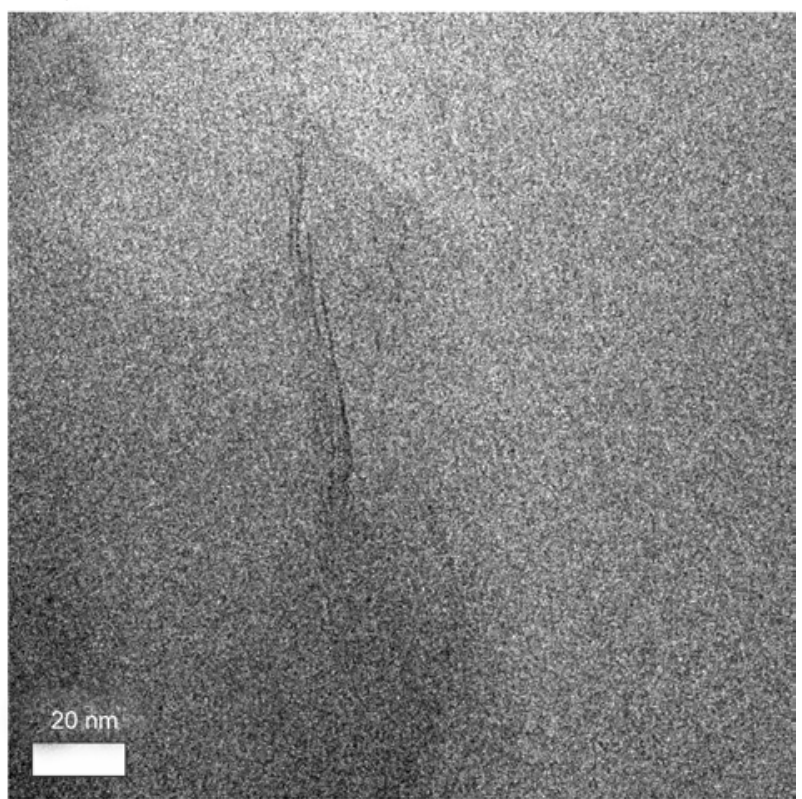

d)

Figure 7. TEM micrographs of melt blended pCBT/PMDI/Cl30B 98/1/1 (a) and (b), and pCBT/PMDI-g-Cl30B 1\% (c) and (d) 
On the other hand, pCBT/PMDI- $g$-Cl30B 1\%-MB in Figure $7 \mathrm{c}$ did not exhibit any sign of clay agglomeration. This sample exhibited a largely exfoliated structure as confirmed by XRD analysis, although some small stacks of a few clay platelets can be seen at high magnification in Figure $7 \mathrm{~d}$. Therefore, the chemical modification of organoclay is a useful method to achieve clay exfoliation.

\subsection{DSC analysis}

The 'as moulded' thermal properties of melt blended and solvent blended pCBT/organoclay nanocomposites are collected in Table 3. Since the processing routes used slightly alter the thermal properties, both melt blended and solvent blended pristine pCBT are shown as reference in the table so that the nanocomposites could be compared to their respective host polymer, depending on the processing route.

The first heating scans of melt blended and solvent blended pCBT/PMDI-g-Cl30B are shown in Figure $8 \mathrm{a}$ and $8 \mathrm{~b}$, respectively. As expected, no significant difference between melt and solvent blended binary blends was found due to equal thermal histories (melt crystallized at ca. $-50^{\circ} \mathrm{C} / \mathrm{min}$ in the cold stage of the hot plate press). All samples exhibited a small amount of cold crystallization in the range of $200-210^{\circ} \mathrm{C}$ with a crystallization enthalpy of -1 to $-2 \mathrm{~J} / \mathrm{g}$. Moreover, all samples showed a pronounced low-temperature melting peak in the temperature range of $222-224^{\circ} \mathrm{C}$ and a high-temperature shoulder around $228^{\circ} \mathrm{C}$. The latter was ascribed to the recrystallization phenomenon [7]. As can be seen from the graphs, melting temperatures as well as melting enthalpies of the nanocomposites slightly decreased with clay content, which is in agreement with published data $[7,16]$. The resulting range of crystallinity was $27-36 \%$. One may expect a relatively tougher behaviour for samples with lower crystal fraction. This was indeed the case for ternary blends, as will be shown later. Nevertheless, the binary samples with low clay loading exhibited a crystal fraction similar to their respective host polymer but showed a considerably higher toughness. This indicates that the degree of crystallinity cannot be solely responsible for the $\mathrm{pCBT}$ brittleness.

Table 3. 'As moulded' thermal properties of melt and solvent blended samples, heating and cooling at $10^{\circ} \mathrm{C} / \mathrm{min}$

\begin{tabular}{|l|c|c|c|c|}
\hline \multicolumn{1}{|c|}{ Sample } & \multicolumn{2}{c|}{ First heating } & \multicolumn{2}{c|}{ First cooling } \\
\hline & $\begin{array}{c}\mathbf{T}_{\mathbf{m}} \\
{\left[{ }^{\circ} \mathbf{C}\right]}\end{array}$ & $\begin{array}{c}\Delta \mathbf{H}_{\mathbf{m}} \\
{[\mathbf{J} / \mathbf{g}]}\end{array}$ & $\begin{array}{c}\mathbf{T}_{\mathbf{c}} \\
{\left[{ }^{\circ} \mathbf{C}\right]}\end{array}$ & $\begin{array}{c}\boldsymbol{\chi}_{\mathbf{c}} \\
{[\% \mathbf{m}]}\end{array}$ \\
\hline pCBT-MB & 224.2 & 51.3 & 193.1 & 36.1 \\
\hline pCBT-SB & 221.6 & 45.3 & 187.2 & 31.9 \\
\hline pCBT/PMDI/Cl30B 98/1/1-MB & 221.3 & 37.8 & 190.9 & 26.6 \\
\hline pCBT/PMDI/Cl30B 98/1/1-SB & 220.5 & 37.7 & 188.2 & 26.5 \\
\hline pCBT/PMDI-g-Cl30B 1\%-MB & 222.4 & 47.4 & 193.5 & 33.4 \\
\hline pCBT/PMDI-g-Cl30B 2\%-MB & 221.5 & 47.0 & 192.4 & 33.1 \\
\hline pCBT/PMDI-g-Cl30B 3\%-MB & 221.9 & 46.2 & 193.2 & 32.5 \\
\hline pCBT/PMDI-g-Cl30B 1\%-SB & 221.4 & 46.7 & 190.7 & 32.9 \\
\hline pCBT/PMDI-g-Cl30B 2\%-SB & 220.9 & 44.0 & 190.4 & 31.0 \\
\hline pCBT/PMDI-g-Cl30B 3\%-SB & 220.9 & 39.4 & 189.7 & 27.7 \\
\hline pCBT100/PMDI/C130B 96/1/3-MB & 221.6 & 39.2 & 193.4 & 27.6 \\
\hline
\end{tabular}
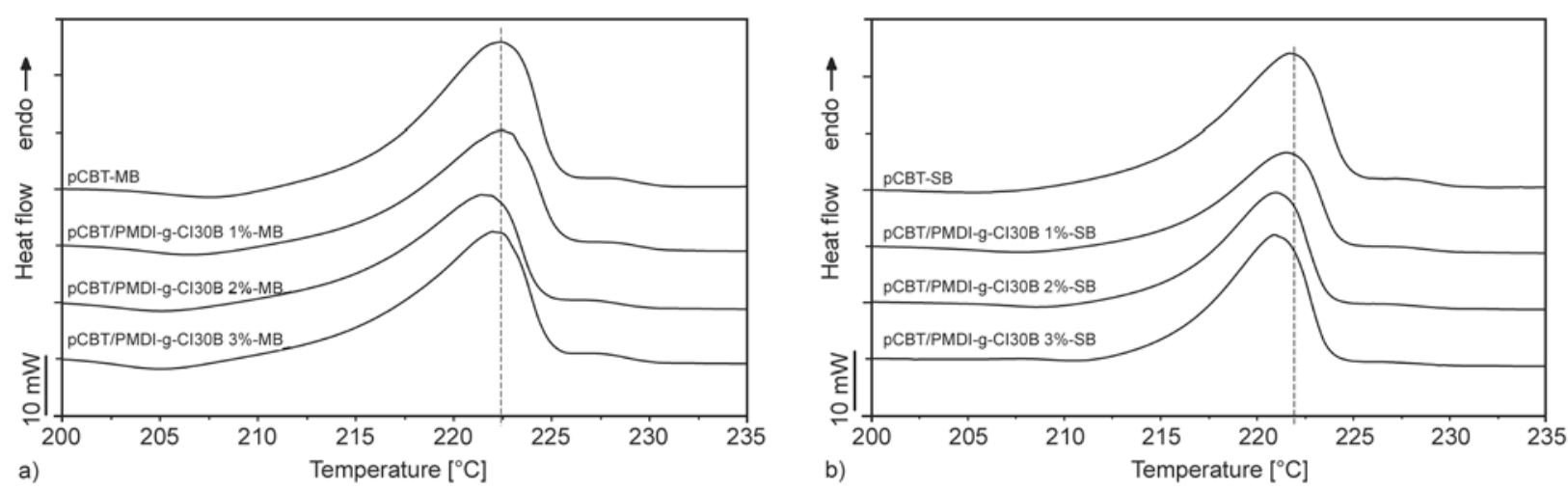

Figure 8. DSC first heating scan of pCBT and pCBT/PMDI- $g$-Cl30B prepared by (a) melt blending and (b) solvent blending; heating and cooling rate of $10^{\circ} \mathrm{C} / \mathrm{min}$ 
Although the clay slightly acts as a nucleation agent, it most likely also confines the polymer chain segments and thus hinders the segmental rearrangement during crystallization and restricts the formation of perfect crystals in the polymer matrix [37]. The enthalpy decrease is more prominent in the ternary blends which can be partially attributed to the effect of chain extension when PMDI was present in the blend (c.f. Table 3).

It was shown that the organoclay used suppresses the cold crystallization when the $\mathrm{CBT} / \mathrm{Cl} 30 \mathrm{~B}$ blend was polymerized in a DSC apparatus during the first heating scan. However, $\mathrm{pCBT} / \mathrm{Cl} 30 \mathrm{~B}$ blends $[7,16]$ as well as PBT/C130B blends [29] exhibited a nucleation effect during melt crystallization. This was also found for solvent blended pCBT/PMDI- $g$ Cl30B blends $\left(\Delta T=3-4^{\circ} \mathrm{C}\right)$. When the latter were melt blended, no nucleation effect was observed. Ternary pCBT/PMDI/Cl30B blends did not show a clear tendency due to an antagonistic effect of clayinduced nucleation and PMDI-induced reduction of $T_{\mathrm{c}}$ [11]. In light of the $6^{\circ} \mathrm{C}$ difference in pCBT crystallization temperature, due to different processing routes or the addition of $1 \mathrm{wt} \%$ of PMDI, the observed nucleation effect $\left(\Delta T=3-4^{\circ} \mathrm{C}\right)$ is not relevant. This also becomes apparent when considering the fact that $\mathrm{Cl} 130 \mathrm{~B}$ was reported to increase $T_{\mathrm{c}}$ by $12-18^{\circ} \mathrm{C}$ in conventional PBT [29].

\subsection{DMTA analysis}

The dynamic mechanical properties of pCBT/organoclay nanocomposites were determined; the dynamic storage modulus curves as a function of temperature are shown in Figure 9. It should be noted that PMDI-grafted pCBT is more flexible than pCBT [11]. Therefore, the nanocomposites were compared

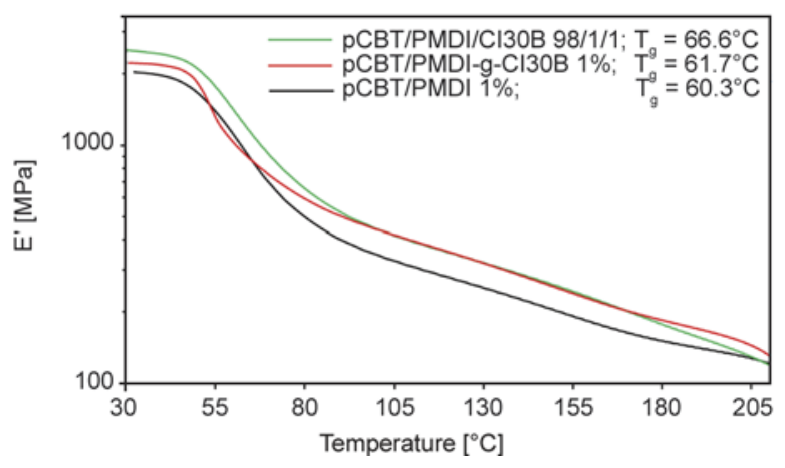

Figure 9. DMTA storage moduli versus temperature of melt blended pCBT/PMDI 1\%, pCBT/PMDI/C130B 98/1/1 and pCBT/PMDI-g-Cl30B 1\% nanocomposites

to melt blended pCBT/PMDI $1 \%$ instead of $\mathrm{pCBT}$ to account for this decreased stiffness.

The nanocomposites exhibited an enhanced stiffness both in the glassy and in the rubbery state as compared to the unreinforced sample. The nanocomposites exhibited a similar thermo-mechanical performance, although pCBT/PMDI/Cl30B ternary blend showed a slightly better performance as compared to the binary blend in the range of the glass transition. The clay modification resulted in a relative stiffness decrease in the glassy state as compared to the ternary blend. Nevertheless, pCBT/ PMDI- $g$-Cl30B showed a reinforcing effect similar to that of the ternary blend in the rubbery state.

\subsection{Tensile properties}

The tensile properties of the prepared nanocomposites, of neat pCBT-MB and of pCBT-SB are compiled in Table 4 for comparison. It should be noted that pristine $\mathrm{pCBT}$ is inherently brittle, irrespective of the different processing routes used herein.

Table 4. Tensile properties of pCBT/organoclay nanocomposites

\begin{tabular}{|l|c|c|c|}
\hline \multicolumn{1}{|c|}{ Sample } & $\begin{array}{c}\text { Tensile modulus } \\
{[\mathbf{G P a}]}\end{array}$ & $\begin{array}{c}\text { Tensile strength } \\
{[\mathbf{M P a}]}\end{array}$ & $\begin{array}{c}\text { Elongation at break } \\
{[\%]}\end{array}$ \\
\hline pCBT-MB & $2.9 \pm 0.3$ & $60 \pm 2$ & $8 \pm 1$ \\
\hline pCBT-SB & $3.0 \pm 0.2$ & $63 \pm 4$ & $8 \pm 2$ \\
\hline pCBT/PMDI/Cl30B 98/1/1-MB & $3.0 \pm 0.4$ & $58 \pm 1$ & $20 \pm 15$ \\
\hline pCBT/PMDI/Cl30B 98/1/1-SB & $3.7 \pm 0.5$ & $62 \pm 2$ & $15 \pm 13$ \\
\hline pCBT/PMDI-g-Cl30B 1\%-MB & $3.2 \pm 0.4$ & $61 \pm 3$ & $9 \pm 3$ \\
\hline pCBT/PMDI-g-Cl30B 2\%-MB & $3.2 \pm 0.2$ & $63 \pm 2$ & $56 \pm 21$ \\
\hline pCBT/PMDI-g-Cl30B 3\%-MB & $3.3 \pm 0.2$ & $66 \pm 1$ & $21 \pm 9$ \\
\hline pCBT/PMDI-g-Cl30B 1\%-SB & $3.0 \pm 0.2$ & $58 \pm 1$ & $4 \pm 2$ \\
\hline pCBT/PMDI-g-Cl30B 2\%-SB & $2.6 \pm 0.1$ & $53 \pm 1$ & $16 \pm 10$ \\
\hline pCBT/PMDI-g-Cl30B 3\%-SB & $2.4 \pm 0.2$ & $50 \pm 6$ & \\
\hline pCBT100/PMDI/Cl30B 96/1/3-MB & $3.2 \pm 0.2$ & $66 \pm 1$ & \\
\hline
\end{tabular}


As expected, $\mathrm{pCBT} / \mathrm{PMDI} / \mathrm{Cl} 30 \mathrm{~B}$ ternary blends exhibited a semi-ductile deformation behaviour with yielding and unstable necking (also indicated by the large standard deviation of the elongation at break in Table 4) along with a stiffness and strength similar to that of pristine pCBT. The solvent blended sample showed a $23 \%$ higher stiffness as well as a moderately increased toughness.

Similarly, melt blended pCBT/PMDI- $g$-Cl30B nanocomposites showed increasing modulus and strength but also decreasing toughness with PMDI- $g$-Cl30B loading. Stiffness and strength were ca. $10 \%$ higher for a clay loading of $3 \mathrm{wt} \%$ as compared to the reference. Contrary to these mechanical properties, solvent blending had a negative effect; the mechanical properties markedly decreased with clay loading. At present it is difficult to explain why solvent blending degrades the mechanical properties. A possible explanation might be clay segregation during the compression moulding step due to the low viscosity of molten CBT prior to ROP and the absence of shear flow during/after polymerization. On the other hand, decreased mechanical properties could be related to THF. THF may have partially remained in the CBT blends after solvent blending, which can be explained by the fact that its chemical structure is similar to the one of the diol-derived portion in $\mathrm{pCBT}$. It was shown that THF can lead to a pCBT with increased ductility but decreased stiffness and strength [38]. Finally, the sample pCBT100/PMDI/Cl30B 96/1/3MB showed a stiffness and strength increase of ca. $10 \%$, respectively, whereas failure strain increased by $100 \%$.

The mechanical properties of the herein prepared samples were compared to literature values from conventional $\mathrm{PBT} / \mathrm{Cl} 30 \mathrm{~B}$ blends and also from $\mathrm{pCBT} /$ organoclay composites. In case of PBT nanocomposites, a clay loading of $3 \mathrm{wt} \%$ resulted in $23-39 \%$ stiffness increase, 6-24\% strength increase and 58$98 \%$ decrease in failure strain $[18,29]$. Regarding pCBT nanocomposites, Wan et al. [20] used $2 \mathrm{wt} \%$ of clay loading and found an increase in stiffness and strength of $13 \%$, respectively, while failure strain was not reported. Hong and co-workers [15] showed that the strength of $\mathrm{pCBT} / \mathrm{Cl} 30 \mathrm{~B} 1 \%$ nanocomposites increased by $13 \%$, while a content of $3 \mathrm{wt} \%$ resulted in only $2 \%$ strength improvement. However, stiffness increased by ca. $10 \%$ when the organoclay content was $3 \mathrm{wt} \%$. No information on failure strain of the pCBT nanocomposites is available but it can be assumed that they were brittle due to the above mentioned pCBT brittleness. Regarding PBT nanocomposites, it is clear that already $1 \mathrm{wt} \%$ of clay loading leads to severe embrittlement with a failure strain below $5 \%$ of the otherwise ductile PBT [18, 29].

The herein reported increase in stiffness and strength is slightly lower as compared to the one described in literature for both pCBT and PBT blends. This is due to the lower stiffness of chain extended pCBT [11]. On the other hand, a semi-ductile behaviour was observed in most of our nanocomposites due to the toughening effect of the isocyanate, either as additive in ternary blends or grafted onto the clay platelets. This demonstrates that the mechanical properties of $\mathrm{pCBT} / \mathrm{Cl} 30 \mathrm{~B}$ nanocomposites can be tailored in a fairly wide range from high stiffness and strength to moderate toughness by adding PMDI or using the proposed clay modification.

\section{Conclusions}

Organically modified montmorillonite was used to prepare isocyanate-toughened $\mathrm{pCBT}$ nanocomposites via melt and solvent blending. The organoclay was further modified by tethering the isocyanate to the clay surfactant in order to improve matrix compatibility. Ternary blends of pCBT/PMDI/C130B showed an intercalated-flocculated structure which resulted in a higher toughness, but also led to a stiffness and strength similar to that of neat pCBT due to an antagonistic effect of organoclay reinforcement and isocyanate toughening. The organoclay modification with isocyanate resulted in an increased interlaminar distance. When this isocyanate-grafted organoclay was reacted with pCBT, clay exfoliation and random dispersion occurred in the pCBT matrix during polymerization. Thermal properties and stabilities were not significantly altered by the organoclay, although some nanocomposites showed a decreased degree of crystallinity. It was demonstrated that the mechanical properties of these nanocomposites can be tailored from high stiffness and strength to moderate toughness using PMDI and the proposed clay modification.

\section{Acknowledgements}

Authors gratefully acknowledge the financial support received from the Spanish Government through the project MAT2013-40730. 


\section{References}

[1] Alexandre M., Dubois P.: Polymer-layered silicate nanocomposites: Preparation, properties and uses of a new class of materials. Materials Science and Engineering R: Reports, 28, 1-63 (2000). DOI: $10.1016 / \mathrm{S} 0927-796 \mathrm{X}(00) 00012-7$

[2] Kiliaris P., Papaspyrides C. D.: Polymer/layered silicate (clay) nanocomposites: An overview of flame retardancy. Progress in Polymer Science, 35, 902-958 (2010).

DOI: 10.1016/j.progpolymsci.2010.03.001

[3] Sinha Ray S., Okamoto M.: Polymer/layered silicate nanocomposites: A review from preparation to processing. Progress in Polymer Science, 28, 1539-1641 (2003).

DOI: 10.1016/j.progpolymsci.2003.08.002

[4] Pattanayak A., Jana S. C.: Synthesis of thermoplastic polyurethane nanocomposites of reactive nanoclay by bulk polymerization methods. Polymer, 46, 32753288 (2005).

DOI: $10.1016 /$ j.polymer.2005.02.081

[5] Mohd Ishak Z. A., Gatos K. G., Karger-Kocsis J.: On the in-situ polymerization of cyclic butylene terephthalate oligomers: DSC and rheological studies. Polymer Engineering and Science 46, 743-750 (2006). DOI: 10.1002/pen.20486

[6] Brunelle D. J., Bradt J. E., Serth-Guzzo J., Takekoshi T., Evans T. L., Pearce E. J., Wilson P. R.: Semicrystalline polymers via ring-opening polymerization: Preparation and polymerization of alkylene phthalate cyclic oligomers. Macromolecules, 31, 4782-4790 (1998).

DOI: $10.1021 / \mathrm{ma} 971491 \mathrm{j}$

[7] Karger-Kocsis J., Shang P. P., Mohd Ishak Z. A., Rösch M.: Melting and crystallization of in-situ polymerized cyclic butylene terephthalates with and without organoclay: A modulated DSC study. Express Polymer Letters, 1, 60-68 (2007).

DOI: $10.3144 /$ expresspolymlett.2007.12

[8] Parton H., Baets J., Lipnik P., Goderis B., Devaux J., Verpoest I.: Properties of poly(butylene terephthatlate) polymerized from cyclic oligomers and its composites. Polymer, 46, 9871-9880 (2005).

DOI: $10.1016 /$ j.polymer.2005.07.082

[9] Wunderlich B.: Crystallization during polymerization. Angewandte Chemie International Edition in English, 7, 912-919 (1968). DOI: $10.1002 /$ anie.196809121

[10] Yu T., Wu C. M., Chang C. Y., Wang C. Y., Rwei S. P.: Effects of crystalline morphologies on the mechanical properties of carbon fiber reinforcing polymerized cyclic butylene terephthalate composites. Express Polymer Letters, 6, 318-328 (2012).

DOI: $10.3144 /$ expresspolymlett.2012.35
[11] Abt T., Martínez de Ilarduya A., Bou J. J., SánchezSoto M.: Isocyanate toughened pCBT: Reactive blending and tensile properties. Express Polymer Letters, 7, 172-185 (2013).

DOI: $10.3144 /$ expresspolymlett.2013.16

[12] Abt T., Sánchez-Soto M., Martínez de Ilarduya A.: Toughening of in situ polymerized cyclic butylene terephthalate by chain extension with a bifunctional epoxy resin. European Polymer Journal, 48, 163-171 (2012).

DOI: $10.1016 /$ j.eurpolymj.2011.10.017

[13] Berti C., Binassi E., Colonna M., Fiorini M., Zuccheri T., Karanam S., Brunelle D. J.: Improved dispersion of clay platelets in poly(butylene terephthalate) nanocomposite by ring-opening polymerization of cyclic oligomers: Effect of the processing conditions and comparison with nanocomposites obtained by melt intercalation. Journal of Applied Polymer Science, 114, 3211-3217 (2009).

DOI: 10.1002/app.30957

[14] Dion R., Bank D., Beebe M., Walia P., LeBaron P., Oelberg J., Barger M., Paquette M., Read M.: Polymerized macrocyclic oligomer nanocomposite compositions. U.S. Patent 20050059768A1, USA (2005).

[15] Hong Y., Yoon H., Lim S.: Preparation of PBT/clay nanocomposites using supercritical process. International Journal of Precision Engineering and Manufacturing, 10, 115-118 (2009).

DOI: $10.1007 / \mathrm{s} 12541-009-0055-7$

[16] Lanciano G., Greco A., Maffezzoli A., Mascia L.: Effects of thermal history in the ring opening polymerization of CBT and its mixtures with montmorillonite on the crystallization of the resulting poly(butylene terephthalate). Thermochimica Acta, 493, 61-67 (2009). DOI: $10.1016 /$ j.tca.2009.04.004

[17] Lee S-S., Ma Y. T., Rhee H-W., Kim J.: Exfoliation of layered silicate facilitated by ring-opening reaction of cyclic oligomers in PET-clay nanocomposites. Polymer, 46, 2201-2210 (2005).

DOI: $10.1016 /$ j.polymer.2005.01.006

[18] McLauchlin A., Bao X., Zhao F.: Organoclay polybutylene terephthalate nanocomposites using dual surfactant modified montmorillonite prepared by the masterbatch method. Applied Clay Science, 53, 749753 (2011). DOI: $10.1016 /$ j.clay.2011.07.006

[19] Tripathy A. R., Burgaz E., Kukureka S. N., MacKnight W. J.: Poly(butylene terephthalate) nanocomposites prepared by in-situ polymerization. Macromolecules, 36, 8593-8595 (2003).

DOI: $10.1021 / \mathrm{ma} 021364+$

[20] Wan C., Zhao F., Bao X., Kandasubramanian B., Duggan M.: Surface characteristics of polyhedral oligomeric silsesquioxane modified clay and its application in polymerization of macrocyclic polyester oligomers. The Journal of Physical Chemistry B, 112, 1191511922 (2008).

DOI: $10.1021 / j p 805259 q$ 
[21] Wu F. M., Yang G. S.: Poly(butylene terephthalate)/ organoclay nanocomposites prepared by in-situ bulk polymerization with cyclic poly(butylene terephthalate). Materials Letters, 63, 1686-1688 (2009).

DOI: 10.1016/j.matlet.2009.05.011

[22] Huang X., Lewis S., Brittain W. J., Vaia R. A.: Synthesis of polycarbonate-layered silicate nanocomposites via cyclic oligomers. Macromolecules, 33, 2000-2004 (2000).

DOI: $10.1021 / \operatorname{ma991709x}$

[23] González-Vidal N., Muñoz-Guerra S., Martínez de Ilarduya A., Benali S., Peeterbroeck S., Dubois P.: Poly (hexamethylene terephthalate)-layered silicate nanocomposites. European Polymer Journal, 46, 156-164 (2010).

DOI: $10.1016 /$ j.eurpolymj.2009.10.018

[24] Cao X., James Lee L., Widya T., Macosko C.: Polyurethane/clay nanocomposites foams: Processing, structure and properties. Polymer, 46, 775-783 (2005). DOI: $10.1016 /$ j.polymer.2004.11.028

[25] Wang H-H., Chen K-V.: A novel synthesis of reactive nano-clay polyurethane and its physical and dyeing properties. Journal of Applied Polymer Science, 105, 1581-1590 (2007).

DOI: 10.1002/app.25955

[26] Xu Z-B., Kong W-W., Zhou M-X., Peng M.: Effect of surface modification of montmorillonite on the properties of rigid polyurethane foam composites. Chinese Journal of Polymer Science, 28, 615-624 (2010). DOI: $10.1007 / \mathrm{s} 10118-010-9111-0$

[27] Esposito Corcione C., Prinari P., Cannoletta D., Mensitieri G., Maffezzoli A.: Synthesis and characterization of clay-nanocomposite solvent-based polyurethane adhesives. International Journal of Adhesion and Adhesives, 28, 91-100 (2008).

DOI: $10.1016 /$ j.ijadhadh.2006.12.004

[28] Indennidate L., Cannoletta D., Lionetto F., Greco A., Maffezzoli A.: Nanofilled polyols for viscoelastic polyurethane foams. Polymer International, 59, 486-491 (2010).

DOI: $10.1002 /$ pi.2726

[29] Chang Y-W., Kim S., Kyung Y.: Poly(butylene terephthalate)-clay nanocomposites prepared by melt intercalation: Morphology and thermomechanical properties. Polymer International, 54, 348-353 (2005).

DOI: $10.1002 /$ pi. 1686
[30] Li X., Kang T., Cho W-J., Lee J-K., Ha C-S.: Preparation and characterization of poly(butyleneterephthalate)/organoclay nanocomposites. Macromolecular Rapid Communications, 22, 1306-1312 (2001).

DOI: 10.1002/1521-3927(20011101)22:16<1306::aidmarc1306>3.0.co;2-i

[31] Kim Y., White J. L.: Formation of polymer nanocomposites with various organoclays. Journal of Applied Polymer Science, 96, 1888-1896 (2005).

DOI: $10.1002 / a p p .21581$

[32] Berti C., Fiorini M., Sisti L.: Synthesis of poly(butylene terephtahlate) nanocomposites using anionic clays. European Polymer Journal, 45, 70-78 (2009).

DOI: $10.1016 /$ j.eurpolymj.2008.09.039

[33] Xiao J., Hu Y., Wang Z., Tang Y., Chen Z., Fan W.: Preparation and characterization of poly(butylene terephthalate) nanocomposites from thermally stable organic-modified montmorillonite. European Polymer Journal, 41, 1030-1035 (2005). DOI: $10.1016 /$ j.eurpolymj.2004.11.025

[34] Yin L., Shi D., Liu Y., Yin J.: Toughening effects of poly(butylene terephthalate) with blocked isocyanatefunctionalized poly(ethylene octene). Polymer International, 58, 919-926 (2009). DOI: $10.1002 /$ pi.2613

[35] Brunelle D. J.: Cyclic oligomer chemistry. Journal of Polymer Science Part A: Polymer Chemistry, 46, 1151-1164 (2008). DOI: $10.1002 /$ pola.22526

[36] Hall A. J., Hodge P.: Recent research on the synthesis and applications of cyclic oligomers. Reactive and Functional Polymers, 41, 133-139 (1999). DOI: $10.1016 / \mathrm{S} 1381-5148(99) 00036-\mathrm{X}$

[37] Pavlidou S., Papaspyrides C. D.: A review on polymer-layered silicate nanocomposites. Progress in Polymer Science, 33, 1119-1198 (2008). DOI: $10.1016 / \mathrm{j}$. progpolymsci.2008.07.008

[38] Abt T., Sánchez-Soto M., Illescas S., Aurrekoetxea J., Sarrionandia M.: Toughening of in situ polymerized cyclic butylene terephthalate by addition of tetrahydrofuran. Polymer International, 60, 549-556 (2011). DOI: $10.1002 /$ pi.2977 